DOI: $10.47456 / k r k r . v 1 i 4.31844$

\title{
Educação do campo e sua trajetória no ensino em Pau dos Ferros - RN
}

\author{
The countryside education and its teaching trajectory, in Pau dos Ferros-RN \\ Geralda Maria de Bem \\ Cícero Nilton Moreira da Silva
}

\begin{abstract}
Resumo Considerando que os sujeitos precisam pensar o mundo a partir do lugar de onde vivem, e sendo o campo seu lugar de fala, é nele que eles devem ser educados como sujeitos de história, vinculados às lutas sociais. Evidentemente que a identidade das escolas do campo tem como pressuposto questões inerentes à sua realidade, levando em consideração os saberes próprios dos educandos, bem como sua forma de pensar o mundo e saber escutar o outro diante das suas particularidades. Este artigo tem como objetivo analisar a trajetória do ensino nas escolas com turmas multianos situadas no campo pauferrense (RN). Adotamos como abordagem metodológica, a pesquisa bibliográfica, estudando os autores: Caldart (2011), Arroyo, Caldart e Molina (2011,) Vendramini (2007), Fernandes (1999), Souza (2012), bem como as Diretrizes Operacionais para a Educação Básica nas escolas do Campo, dentre outras referências que abordam a temática em estudo. Em síntese, este trabalho nos evidenciou a necessidade de aprofundarmos nossa reflexão acerca da Educação do Campo e os aspectos que permeiam o ensino nas escolas com turmas multianos, visto que o campo é um espaço vivo. É nele que os sujeitos se mobilizam, produzindo uma dinâmica social e cultural, tendo a educação e a escola como foco de debate dessa dinâmica educativa dos diversos povos do campo.
\end{abstract}

Palavras-chave: Educação do Campo. Turmas multianos. Ensino.

Abstract Considering that the subjects need to think about the world from the place where they live, and the field is its own place, is in it that the subjects must be educated as subjects of history, linked to social struggles. Evidently, the identity of rural schools is based on the questions inherent to their reality, taking into account the knowledge of the students, as well as their way of thinking about the world and knowing how to listen to the other in the face of their particularities. This article aims to analyze the trajectory of teaching in schools with multi-years classrooms located in the countryside of Pau dos Ferros. We adopt a bibliographic research as a methodological approach, studying the authors: Caldart (2011), Arroyo, Caldart e Molina (2011,) Vendramini (2007), Fernandes (1999), Souza (2012), as well as the Operational Guidelines for Basic Education in Countryside schools, among other references that address the theme under study. In summary, this paper showed us the need to deepen our reflection about Rural Education and the aspects that permeate teaching in schools with multi-years classrooms, since the countryside is a living space. It is in countryside that the subjects mobilize themselves, producing a social and cultural dynamics, with education and the school as the focus of debate on this educational dynamics of the diverse peoples of the countryside.

Keywords: Countryside Education. Multi-years Calssrooms. Teaching. 


\section{Introdução}

Sabemos que o problema da educação no Brasil não é exclusivo do meio rural, porém devemos ressaltar que, nesse meio, a situação educacional é mais crítica, devido a diversos fatores, principalmente a ausência de políticas públicas destinadas para essa modalidade de ensino. Para Caldart (2011, p. 49), "um dos problemas do campo hoje é a ausência de políticas públicas que garantam seu desenvolvimento em formatos adequados à melhoria da qualidade de vida das pessoas que ali vivem e trabalham".

E, ainda, conforme Caldart (2011), a escola do campo é aquela que trabalha visando aos interesses, à política e à cultura dos diversos grupos existentes no campo. Nesse sentido, vale ressaltar que, ao pensarmos essa escola, no contexto atual, devemos pensar numa escola que esteja voltada para o compromisso com os valores e com a cultura dos povos campesinos.

Este artigo é fruto de um estudo dissertativo a respeito da prática docente e sua atuação na Educação do Campo no município de Pau dos Ferros/RN. Desse modo, objetivamos analisar a trajetória do ensino nas escolas com turmas multianos situadas no campo pauferrense. Para tanto, adotamos como abordagem metodológica a pesquisa bibliográfica, estudando os autores: Arroyo, Caldart e Molina (2011), Vendramini (2007), Souza (2012) Barreto (1987), dentre outros que tratam da temática em estudo. Respaldamo-nos, ainda, nas Diretrizes Operacionais para a Educação Básica nas Escolas do Campo (Brasil, 2002), que trata sobre a proposta pedagógica, abordando sobre os modos próprios de vida dos sujeitos que vivem no campo.

De acordo com os pressupostos teóricos de Fernandes (2011), a educação básica do campo tem um papel fundamental, sobretudo no que diz respeito ao exercício da cidadania dos diversos povos que vivem no campo, a qual contribui para o desenvolvimento e para a formação humana dos mesmos. Considerando que os sujeitos precisam pensar o mundo a partir do lugar onde vivem, e sendo o campo seu lugar de fala, é nele que os sujeitos devem ser educados como sujeitos de história, vinculados às lutas sociais.

Sendo assim, o presente texto está organizado em três partes: na primeira, procuramos entender, de forma sucinta, a concepção de Educação do 
Campo; já no segundo momento, nos atentaremos para compreender a trajetória do ensino nas escolas do campo, especialmente no município de Pau dos Ferros-RN; por fim, no terceiro momento abordamos sobre os aspectos históricos e geográficos que permeiam as escolas pesquisadas.

\section{Concepção de Educação do Campo: breve histórico}

Ao abordarmos a Educação do Campo devemos ressaltar que é preciso acreditar que o campo é um lugar vivo, um dos território social, econômico e político no qual os sujeitos podem lutar de forma coletiva, sobretudo em prol de políticas públicas; dentre elas, uma educação que seja voltada para a realidade dos povos campesinos.

De acordo com Caldart (2004, p. 28), "a Educação do Campo precisa aprofundar a reflexão sobre como a escola pode ajudar a cultivar utopias e a formar militantes, respeitando a cultura camponesa e a própria fase da vida em que se encontram os diferentes educandos". Desse modo, a escola do campo tem como finalidade desenvolver uma proposta de trabalho que seja capaz de redesenhar as práticas pedagógicas dos professores que atuam nessas escolas, na perspectiva de buscar conhecimentos para mediar o processo ensino aprendizagem dos educandos do campo.

A Educação do Campo traduz a luta popular por uma escola pública de direito e de qualidade no campo, para os sujeitos que vivem nesse espaço, visto que as pessoas precisam ser educadas no ambiente onde vivem. Caldart (2011) afirma que o silenciamento sobre o rural e o esquecimento deste, nas pesquisas sociais e educacionais, é um dado histórico na história dos povos do campo, tornando-se algo preocupante. Assim sendo, o movimento da Educação do Campo nasceu para denunciar, sobretudo esse silenciamento por parte dos órgãos responsáveis pelos estudos das pesquisas direcionadas à Educação do Campo. É fato que, nos últimos vinte anos, a população despertou para uma nova visão de que o campo está vivo. É nele que os sujeitos se mobilizam, produzindo uma dinâmica social e cultural, tendo a educação e a escola como foco de debate dessa dinâmica social, cultural e educativa dos diversos povos que vivem no campo. Assim, para Caldart (2011, p, 11- 12), 
[...] a Educação do Campo nasce sobretudo de um outro olhar sobre o papel do campo em um projeto de desenvolvimento e sobre os diferentes sujeitos do campo. Um olhar que projeta o campo como espaço de democratização da sociedade brasileira e de inclusão social, e que projeta seus sujeitos como sujeitos de história e de direitos; como sujeitos coletivos de sua formação enquanto sujeitos sociais, culturais, éticos e políticos.

As discussões sobre a Educação do Campo, no âmbito das pesquisas educacionais, deverão reconhecer a mobilização dos movimentos sociais do campo, no que concerne aos aspectos educacionais, através das lutas dos sujeitos pela ação educativa e seus processos formadores, como seres humanos que fazem parte de uma sociedade. Conforme pontual Arroyo, Caldart e Molina (2011, p. 12-13),

A Educação do Campo traz, então, uma grande lição e um grande desafio para o pensamento educacional: entender os processos educativos na diversidade de dimensões que os constituem como processos sociais, políticos e culturais; formadores do ser humano e da própria sociedade.

De fato, deve-se considerar o direito à educação e à escolarização dos sujeitos que vivem no campo, pois a educação é um direito social e humano. Portanto, é imprescindível respeitar os convívios, a dinâmica social, cultural do local de onde os sujeitos estão inseridos, de modo que a escola do campo deve estar vinculada à identidade dos grupos sociais que convivem ali. A luta pelo direito ao acesso à escola do campo é um direito de todos, em defesa de uma escola pública que possa contribuir na formação de conhecimento, na cultura, valores e identidades dos povos campesinos - crianças, adolescentes, jovens e adultos.

De acordo com Vendramini (2007, p. 129), "a educação do campo ganha um novo sentido, quando associada a um movimento social que defende a educação articulada com a criação de condições materiais para a vida no campo". E, ainda, segundo essa mesma autora, esta perspectiva de Educação do Campo tem como base o reconhecimento da realidade de trabalhadores e trabalhadoras que, no decorrer da história, têm resistido em continuar produzindo sua vida no espaço rural. Para Fernandes (1999, p. 65), "uma escola do campo é a que defende os interesses, a política, a cultura e a economia da agricultura camponesa, que construa conhecimentos e tecnologia na direção do 
desenvolvimento social e econômico dessa população". Assim, pensar numa educação do campo é estar refletindo sobre as mudanças e os desafios que implicam essa modalidade de ensino.

Seguindo a mesma óptica, Souza (2012, p.16) assinala que

A Educação do Campo nasceu dos pensamentos, desejos e interesses dos sujeitos do campo, que nas últimas décadas intensificaram suas lutas, espacializando-se e territorializandose formando territórios concretos e imateriais.

Nas duas últimas décadas, a Educação do Campo vem sendo discutida em dissertações, teses e livros, como por exemplo, os livros: A Educação Básica e o Movimento Social do Campo, de Arroyo e Fernandes (1999), e Por uma Educação Básica do Campo, de Kolling; Nery; Molina (1999); os quais tratam da trajetória da Educação do Campo e das políticas públicas educacionais. Esta ocorre tanto nos espaços escolares quanto fora deles; e envolve saberes, métodos, tempos e espaços físicos diferenciados.

É importante ressaltar que, desde 2001, foram aprovadas as Diretrizes Operacionais para a Educação Básica nas escolas do campo no Brasil, tendo como finalidade trabalhar a proposta curricular de acordo com a realidade dos povos que habitam o campo, tais como: caiçaras, ribeirinhos, indígenas, agricultores, moradores de assentamentos, dentre outros; trabalhando-se de forma integrada, currículo e cultura local.

Portanto, é preciso olhar a Educação do Campo numa perspectiva que compreenda a dimensão cultural e sociocultural dos sujeitos que habitam no campo e que, coletivamente, lutam por políticas que estejam vinculadas a sua identidade, enquanto seres históricos que pertencem a uma sociedade.

\section{Trajetória do ensino nas escolas do campo no município de Pau dos Ferros-RN}

Neste tópico, buscamos compreender a trajetória do ensino nas escolas com turmas multianos, que se situam no campo, no município de Pau dos FerrosRN. Nessa perspectiva, iniciaremos fazendo um breve relato da história do município, que teve sua origem através das atividades pastoris, devido às excelentes condições do solo como também de uma vegetação fértil. 
Conforme assinale Barreto (1987), é importante destacar, inicialmente, que a pecuária foi de grande importância no setor econômico, em face da sua relevância como sendo fornecedora de gêneros alimentícios e fonte de matériaprima para a produção de couro; logo o gado foi um dos elementos indispensáveis no episódio de povoamento da região.

No que diz respeito à educação, segundo Barreto (1987, p. 76 -77),

Em Pau dos Ferros não existiu nenhuma escola régia. Os habitantes da antiga freguesia tiveram de adquirir noções rudimentares de leitura e escrita com os mestre-escolas que nas fazendas, mediante pequena remuneração, se dedicavam à árdua tarefa de desarnar os filhos dos fazendeiros, de seus moradores e vaqueiros.

Ainda quanto à educação do campo de Pau dos Ferros, a primeira escola pública que funcionou na cidade, segundo Barreto (1987), foi criada pela Lei Provincial $\mathrm{n}^{\circ} 11$, de 9 de março de 1835 , e funcionava das $7 \mathrm{~h}$ às $11 \mathrm{~h}$ e das $15 \mathrm{~h}$ às 18h, para a qual foi nomeado o professor João Gualberto Soares da Câmara, que foi removido para a cidade de Portalegre (RN), ficando a escola sem professor por alguns anos. Foi criada nova escola de primeiras letras para o sexo masculino, pela resolução Provincial $n^{\circ} 213$, de 5 de junho de 1850 . Nesse período, ignora-se a data da criação de escola para o sexo feminino. Assim, no decorrer da trajetória da história da educação de Pau dos Ferros, foram surgindo outras escolas estaduais, municipais e privadas, bem como a criação da Universidade pública, em 1976, que continua se expandindo até os dias atuais.

Analisando esse contexto, compreendemos que a escolarização rural, desde sua origem, foi destinada para que as pessoas não adquirissem conhecimentos mais sistematizados e em níveis mais elevados, sendo instruídas a conhecer as primeiras letras, como também os números; o que já era considerado suficiente para a formação das classes menos favorecidas. Fica entendido que, nessas escolas, àquela época, se priorizava mais a leitura, a escrita e os números. Conforme o ensino descrito por Barreto (1987), isso nos mostra a negligência com a educação do campo no município, cuja realidade está pautada em um ensino rotineiro. Nesse sentido, percebemos que uma educação básica do campo deve primar por um ensino nas escolas que considere o vínculo que os sujeitos possuem com sua comunidade e sua luta 
sociopolítica, passando pelos interesses sociais, culturais, numa concepção ampla de educação que seja universal para todos os sujeitos, e que leve em conta, particularmente, sua história de vida, enquanto sujeitos sociais e concretos que fazem parte da localidade onde estão inseridos.

Contudo, no que diz respeito a essas escolas, temos observado, continuamente, uma política de fechamento/nucleação destas, no cenário da educação brasileira; o que tem acontecido conforme Vendramini (2007, p. 123), com o seguinte objetivo:

[...] racionalizar a estrutura e a organização de pequenas escolas, em comunidades que contam com um reduzido número de crianças em idade escolar, e diminuir o número de classes multisseriadas, orientando-se pelo Plano Nacional de Educação (Projeto de Lei n. 4.173/98).

Dessa forma, diante dos desafios que a escola do campo vem enfrentando, faz-se necessário discutir o que tem sido planejado pela Secretaria de Educação do Município de Pau dos Ferros (RN), a fim de tentar mudar essa realidade.

Entre os principais motivos do fechamento das escolas do campo nesse município, merecem destaque: a) o descrédito por parte dos pais com relação ao ensino e à aprendizagem dos filhos, em virtude da multisseriação; portanto esse parece ser o maior problema; b) o deslocamento das crianças do campo para a cidade, o que mudaria se a escola oferecesse infraestrutura adequada, professor qualificado, e material didático; c) a ausência da equipe pedagógica na escola do campo, cujos profissionais alegam falta de garantia de transporte para o trajeto cidade-campo; entre outros.

Cabe aqui reafirmar a necessidade de a Educação do Campo estar voltada para a luta dos povos por educação, saúde e trabalho, que garanta a sobrevivência do trabalhador e da trabalhadora que vivem no campo. Segundo Caldart (2004, p. 25), "É tarefa específica da escola, ajudar a construir um Ideário que orienta a vida das pessoas e inclui também as ferramentas culturais de uma leitura mais precisa da realidade em que vivem". Assim, para ajudar esses sujeitos a construir uma visão de mundo, é necessário que os educadores e educandos se compreendam como sujeitos que reconhecem a si, como pessoas 
que fazem parte de um processo histórico. Tudo isso contribui para que os sujeitos possam interpretar, organizar e firmar suas ideias, convicções sobre o mundo, a sua história e a realidade e, sobretudo, compreender a si mesmos.

Sendo assim, é necessário que os educadores, que trabalham nas escolas do campo, possam compreender a realidade dos educandos, e procurem mobilizá-los sobre a sua importância na participação ativa nos movimentos sociais e na luta no campo das políticas públicas, para que possam beneficiar a todos os educandos do campo com o acesso à educação.

\section{Concepções sobre os aspectos históricos e geográficos que permeiam as escolas pesquisadas}

Ao relatar sobre o percurso das escolas pesquisadas, em primeiro lugar, faz-se necessário um olhar aguçado sobre os aspectos históricos e geográficos que pautam o território em que essas escolas estão localizadas, no que diz respeito às relações destes com os fatores econômicos que permearam as localidades das escolas em estudo. Através de entrevistas com os sujeitos que foram moradores daqueles sítios, em décadas passadas, foi possível ter uma visão dessas realidades.

Segundo Rocha e Martins (2012, p. 31), "na escola do campo, a realidade é uma totalidade, por isto não há como partir dela, para seguir adiante ou retornar. Com seus diferentes territórios, constitui-se como o locus que se quer transformar". Assim, cada escola possui seu próprio território, que se articula de acordo com a especificidade dos sujeitos que nele habitam.

É importante ressaltar que, nas últimas décadas do século $X X$, era visível a existência da agricultura de subsistência dos pequenos agricultores que viviam no espaço rural do município. Assim sendo, nas localidades onde estão situadas as escolas pesquisadas predominou, por longos anos, o cultivo da agricultura de subsistência. Segundo uma conversa que tivemos com um ex-morador de uma daquelas localidades, este nos relatou que nos sítios, onde hoje estão localizadas tais unidades escolares, os pequenos agricultores costumavam fazer seu plantio para o sustento de sua família.

$\mathrm{Na}$ escola localizada na região da barragem, a economia se baseava, principalmente, na criação de peixe, através da Associação dos Pescadores, por 
existir abundante água naquela localidade. Por isso, havia também a predominância de criação de animais, como o gado, por exemplo.

Em outra escola do campo de pesquisa, localizada no Sítio Sorriso, segundo esse mesmo morador, existia um engenho que movimentava a economia do lugar, através da moagem de cana de açúcar e da fabricação de rapadura; também era atividade econômica a criação de gado. Atualmente, o engenho encontra-se desativado, e a economia do lugar está baseada numa criação mínima de animais, e na existência de pequenas lavouras temporárias; tendo desaparecido o plantio da cana de açúcar.

Em conversa com outro morador, este nos afirmou que, nos demais sítios, no passado predominavam o plantio de algodão, milho, arroz, entre outras plantações e criação de animais de modo extensivo (criatório solto no pasto).

Verificamos, na fala desses sujeitos, a predominância da agricultura de subsistência dos pequenos agricultores que residiam nas localidades próximas às escolas. Isso nos mostra que as condições climáticas favoreciam para que ocorresse esse período de plantio, como também a criação de animais e de peixe, este último, em criatório situado na barragem; sendo tudo isso de grande relevância para os pequenos agricultores.

Nesse sentido, a Educação do Campo é tida como um território ou dimensões territoriais, ainda que os territórios sejam denominados de espaços geográficos e políticos, em que os sujeitos discutem e planejam as lutas nos movimentos sociais.

Para Fernandes (2012, p. 15),

Os Territórios da Educação do Campo nos desafiam para construirmos as condições educacionais apropriadas para o desenvolvimento de um modo de vida em que a família, a terra, o alimento, a comunidade, a escola, o movimento, as pessoas, o trabalho estão acima da mercadoria.

Sendo assim, o cooperativismo é um dos aspectos fundamentais para a vivência dos sujeitos que residem no campo, sendo que a mercadoria não está em primeiro lugar, ou seja, como no território de uma educação capitalizada. Ao contrário, a produção será resultado dessas relações sociais entre os pequenos 
agricultores nos territórios de Educação do Campo. Dessa forma, as escolas da Educação do Campo, ao nascerem, já trazem no bojo as dimensões da luta pela conquista da lida nas condições de trabalho, bem como do modo de produção da vida camponesa.

Neste sentido, é preciso pensar num currículo que valorize a experiência, a identidade, e a cultura dos educandos que convivem nesse espaço. O direito dos educandos de estudar próximo a sua residência é um dos fatores que contribui para que não ocorra evasão escolar. Esse direito está respaldado na Lei de Diretrizes e Bases da Educação Nacional LDBEN 9394/96 Brasil (1996), no art. 4. Inciso $X$, que "garante vaga na escola pública de educação infantil ou de ensino fundamental mais próxima de sua residência a toda criança a partir do dia em que completar quatro anos de idade". Desse modo, a escola costuma ser uma das primeiras instituições em que as crianças se relacionam com outras pessoas que são do seu ambiente familiar, e tem essa finalidade de oferecer um espaço socializador.

\section{Considerações finais}

Vimos, no decorrer do texto, que a Educação do Campo traduz a luta popular por uma escola pública de direito e de qualidade no campo, para os sujeitos que vivem nesse espaço, visto que as pessoas precisam ser educadas no ambiente onde vivem. A mesma se preocupa com a formação de seres humanos, especificamente com a educação do conjunto da população trabalhadora do campo, levando em consideração sua história, sua cultura e as lutas sociais.

É fato que, nos últimos vinte anos, a população despertou para uma nova visão de que o campo está vivo. É nele que os sujeitos se mobilizam, produzindo uma dinâmica social e cultural, tendo a educação e a escola como foco de debate dessa dinâmica social, cultural e educativa dos diversos povos que vivem no campo. Dessa forma, para entendermos melhor o contexto escolar, devemos compreender que o movimento no campo abrange todos os sujeitos - homens, mulheres, crianças e jovens - que se integram em prol do movimento social. 
Sendo assim, a escola deve considerar a história, a diversidade cultural dos educandos e sua formação humana.

Nesses termos, baseados no estudo da realidade posta em análise, constatamos que, como cada educando possui sua especificidade, assim como o/a professor/professora também possui sua história de vida e sua diversidade, sendo, portanto, sujeitos em construção, que precisam conhecer a história de seus educandos, sendo esta uma das características essenciais da educação básica no campo, como também uma característica dos movimentos sociais, que tem como finalidade a valorização dos sujeitos.

\section{Referências}

ARROYO, Miguel Gonzalez; CALDART, Roseli Salete; MOLINA, Monica Castagana. (Org.). Por uma educação do campo. $5^{\mathrm{a}}$ ed. Petrópolis, Rio de Janeiro: Editora Vozes. 2011. p. 7-18.

ARROYO, Miguel Gonzalez; FERNANDES, Bernardo Mançano. A educação básica e o movimento social do campo. Coleção: Por uma educação básica do campo n. ${ }^{\circ} 2$. Brasília, 1999.

BARRETO, José J. Pau dos Ferros: História, Tradição e Realidade. $1^{\text {a }}$ ed. Pau dos Ferros, 1987.

BRASIL, Diretrizes Operacionais para a Educação Básica nas Escolas do Campo. Resolução CNE/CEB 1, de 3 de Abril de 2002

BRASIL. Lei no 9.394, de 20 de dezembro de 1996. Estabelece as diretrizes e bases da educação nacional. Diário Oficial da União. Brasília, dez. 1996.

FERNANDES, Bernardo Mançano. "Diretrizes de uma Caminhada" In: ARROYO, Miguel Gonzalez; CALDART, Roseli Salete; MOLINA, Monica Castagana (Orgs.). Por uma educação do campo. Petrópolis, Rio de Janeiro: Editora Vozes. 2011. p. 133-145.

. "Territórios da educação do campo" In: ROCHA, Maria Isabel Antunes; MARTINS, Maria de Fatima; MARTINS, Aracy Alves. (orgs). Território Educativos na Educação do Campo. 2. ed. Belo Horizonte: Autêntica 2012, p.15-20.

ROCHA, Maria Isabel Antunes. "Licenciatura em educação do campo: histórico e projeto político-pedagógico" In: ROCHA, Maria Isabel Antunes; MARTINS, Aracy Alves. (orgs). Educação do Campo: desafios para a formação de professores, 2. ed. Belo Horizonte: Autêntica 2011, p.39-55.

SOUZA, Maria Antonia de. Educação do campo: proposta e prática pedagógica do MST, $2^{\mathrm{a}}$ ed. Petrópolis, Rio de Janeiro: Vozes, 2012. 
VENDRAMINI, Célia Regina. Educação e trabalho: reflexões em torno dos movimentos sociais do campo. Caderno Cedes - Educação do Campo. Campinas, v. 27, n. 72, p.17-20, maio/ago.2007. Disponível em <http:www.scielo.br/scielo.php?pid=S010132622007000200002\&script=sci_artt ext\&tlng=pt\#nt>. acesso em: 21 julho de 2020.

Sobre os Autores

\section{Geralda Maria de Bem}

geraldabem@hotmail.com

Mestra em Ensino pela Universidade do Estado do Rio Grande do Norte (UERN); Professora da Secretaria Municipal de Educação de Pau dos Ferros - Brasil; Pesquisadora e técnica do grupo de pesquisa: Núcleo de Estudos de Geografia Agrária e Regional - NuGAR-UERN.

\section{Cícero Nilton Moreira da Silva}

ciceronilton@yahoo.com.br

Doutor em Geografia pela Universidade Federal do Ceará (UFC); Professor da Universidade do Estado do Rio Grande do Norte - Brasil; Professor do Programa de Pós-graduação em Ensino (PPGE); Pesquisador 